D) Check for updates

Cite this: Food Funct., 2019, 10, 2630

\section{Simulated gastrointestinal digestion of inclusion complexes based on ovalbumin nanoparticles and conjugated linoleic acid}

\author{
Flavia F. Visentini, ${ }^{a, b}$ Joana B. Ferrado, ${ }^{b, c}$ Adrián A. Perez ${ }^{a, b}$ and \\ Liliana G. Santiago iD *b
}

\begin{abstract}
The objective of this work was to obtain and characterize conjugated linoleic acid (CLA) delivery systems based on ovalbumin nanoparticles $\left(O V A_{n 1}\right.$ and $\left.O V A_{n 2}\right)$ and to study their behaviour under a standardised static in vitro digestion model. $\mathrm{OVA}_{n 1}$ and $\mathrm{OVA}_{\mathrm{n} 2}$ were obtained by heat treatment $\left(85^{\circ} \mathrm{C}, 5 \mathrm{~min}, \mathrm{pH} 11.35\right.$ and 7.5, respectively). $O V A_{n 1}$ and $O V A_{n 2}$ had hydrodynamic diameters of $24.63 \pm 0.04$ and $92.0 \pm 0.2 \mathrm{~nm}$, respectively, showing no significant differences in $\zeta$ potential values $(p<0.05)$ at $\mathrm{pH}$ 7.0. CLA nanocomplexes were examined in terms of size and $\zeta$ potential at $\mathrm{pH} 3.0$ and 7.0, highlighting that binding of CLA caused an increase in size for OVA and both OVA nanoparticles. Morphological characterization was performed by confocal laser scanning microscopy (CSLM) finding that OVA and OVA nanoparticles had a circular shape. Also, the CLA encapsulation efficiency (EE) for OVA and OVA nanoparticles was studied, yielding EE values greater than $97 \%$ for all systems. Finally, systems were assayed for a standardized in vitro gastrointestinal digestion model considering gastric and intestinal steps. Macroscopic appearance, CSLM images and quantification of CLA retention by HPLC were evaluated after digestion. All the systems showed the formation of macroscopic aggregates both in gastric and intestinal phases, which generated a visible precipitate. In all systems, CSLM confirmed the presence of numerous undefined-form aggregates. Finally, high CLA retention (around 99\%) was found for native protein and nanoparticles.
\end{abstract}

Received 6th December 2018, Accepted 12th April 2019

DOI: $10.1039 / c 8 f o 02416 b$

rsc.li/food-function human health, including reduction of fat accumulation, ${ }^{4}$ prevention of cardiovascular diseases, ${ }^{5}$ it is involved in immune and inflammatory responses, ${ }^{6}$ in bone health ${ }^{7}$ and it has anticarcinogenic properties. $^{8}$

Nevertheless, in general, PUFAs have very low water solubility and they are susceptible to oxidative deterioration, which decreases its nutritional value. ${ }^{9}$ In particular, CLA exhibits very poor chemical stability showing autoxidation and isomerization. ${ }^{10}$ To overcome these problems, it is necessary to protect/ encapsulate it by using efficient delivery systems. In order to protect PUFAs against oxidation, different encapsulation systems have been developed including protein particles, ${ }^{9}$ micro emulsions, ${ }^{11}$ liposomes, ${ }^{12}$ hydrogels $^{13}$ and systems based in polymers. ${ }^{14}$

Food proteins are biopolymers with excellent properties for encapsulation of bioactive compounds. Usually, food proteins are GRAS (Generally Recognized as Safe), biodegradable and biocompatible materials. These are important properties to promote nutraceutical and pharmaceutical applications. Many globular proteins have the intrinsic ability to bind lipophilic compounds $^{9,15-17}$ and this property could be used as a strategy to protect and introduce CLA into food matrices. In the last years, our research team have focused on the evaluation of 
ovalbumin (OVA), the main protein of egg white protein (EWP), so as to obtain OVA nanoparticles by heat-induced treatment at different environmental $\mathrm{pH}$ conditions. Besides, we have observed that OVA nanoparticles had an increased capacity to bind different lipophilic ligands. ${ }^{17,18}$

In addition, numerous studies show the influence of CLA on colon cancer. ${ }^{3,16,19}$ Mixtures of CLA isomers can alter initiation, promotion, progression and metastasis of malignant tumours through different mechanisms. For example, it is known that CLA isomers affect lipids metabolisms by inhibition of oxygenase pathway or inducing apoptotic genes expression. ${ }^{16}$ A study reported that trans-10, cis-12 CLA isomer induced apoptosis through reactive oxygen species-mediated endoplasmic reticulum stress. ${ }^{19}$

In terms of these evidences, the design of an oral delivery system for CLA could be a promising tool for colon cancer treatment. For this, it is essential to know the behaviour of CLA delivery system under gastrointestinal conditions.

For all the above, the aim of this work was to obtain and characterize CLA delivery systems and mainly, to study their behaviour under a standardised static in vitro digestion model. For this, two nanoparticles were designed based on the OVA intrinsic ability to bind PUFAs. ${ }^{18,20,21}$ These systems were characterized in terms of dynamic light scattering (DLS), confocal laser scanning microscopy (CLSM) and encapsulation efficiency. Finally, in order to get some information about CLA release/retention from OVA nanoparticle in the gastrointestinal tract, an examination by applying a standardised static in vitro digestion model was conducted. ${ }^{22}$

\section{Materials and methods}

\subsection{Materials}

Native ovalbumin (OVA, product A5503, purity 98\% according to agarose gel electrophoresis), conjugated linoleic acid (CLA, O5507), pepsin from porcine gastric mucosa (P7000), pancreatin from porcine pancreas (P7545), bile extract porcine (B8631), hemoglobin (H2500) and $N_{\alpha}-p$-Tosyl-L-arginine methyl ester hydrochloride (TAME, T4626) were purchased from Sigma (USA). These materials were kept according to manufacturer advice. Additional analytical reagents were supplied from Cicarelli (Argentina).

\subsection{Nanoparticles formation}

It is known that $\mathrm{pH}$ is an important variable to obtain heat induced OVA nanoparticles of different sizes. ${ }^{23}$ Therefore, in order to evaluate the influence of particle size on protein nanoparticle digestibility, OVA nanoparticles were produced at two different $\mathrm{pH}$ values. For this, an OVA solution in $50 \mathrm{mM} \mathrm{NaCl}$ was prepared, and $\mathrm{pH}$ values were adjusted at 11.4 and 7.5 by using $1 \mathrm{M} \mathrm{NaOH}$. These protein solutions hydrated overnight at $4{ }^{\circ} \mathrm{C}$. If it were necessary, $\mathrm{pH}$ was readjusted by using $0.1 \mathrm{M}$ $\mathrm{NaOH}$. Then, aliquots of $2 \mathrm{ml}$ were dispensed in glass tubes, and they were heated in a water bath at $85{ }^{\circ} \mathrm{C}$ over $5 \mathrm{~min}$. Subsequently, tubes were removed and immediately cooled in an ice bath. Tubes containing OVA nanoparticles were kept at $4{ }^{\circ} \mathrm{C}$ until further analysis. OVA nanoparticle $1\left(\mathrm{OVA}_{\mathrm{n} 1}\right)$ was prepared at $30 \mathrm{~g} \mathrm{~L}^{-1} \mathrm{OVA}$ and $\mathrm{pH}$ 11.4. For OVA nanoparticle 2 $\left(\mathrm{OVA}_{\mathrm{n} 2}\right), 10 \mathrm{~g} \mathrm{~L}^{-1}$ and $\mathrm{pH} 7.5$ were applied. ${ }^{20}$ It is important to mention that although the production concentrations of both nanoparticles were different, $\mathrm{OVA}_{\mathrm{n} 1}$ and $\mathrm{OVA}_{\mathrm{n} 2}$ were examined at the same concentration during the inclusion complexes formation and all the experimental determinations.

\subsection{Inclusion complexes formation}

Inclusion complexes were produced exploiting the intrinsic ability of OVA and its nanoparticles to bind lipophilic compounds. ${ }^{17,18,20,21}$ In this work, OVA, $\mathrm{OVA}_{\mathrm{n} 1}$ and $\mathrm{OVA}_{\mathrm{n} 2}$ solutions in phosphate buffer $50 \mathrm{Mm}$ pH 7.0 were mixed with an ethanolic solution of $0.1 \mathrm{M}$ CLA to form the inclusion complexes. In order to reach the equilibrium, the protein-CLA inclusion complexes were left in darkness for $2 \mathrm{~h},{ }^{21}$ and they were immediately used.

\subsection{Experiment design}

In first place, the effect of $\mathrm{pH} 3.0$ and 7.0 on physicochemical and structural properties of OVA, OVA nanoparticles and OVA nanoparticles-CLA inclusion complexes were evaluated. For this, OVA, OVA nanoparticles and protein-CLA inclusion complexes were produced at $\mathrm{pH} 7.0$ and then the $\mathrm{pH}$ was lowered to 3.0 by using $1 / 0.1 \mathrm{M} \mathrm{HCl}$.

In second place, all systems were evaluated through a simulated gastrointestinal digestion assay consisting of in vitro gastric and intestinal phases. This assay was divided in two experiments: (i) SGF without enzymes and SIF without enzymes and (ii) SGF + enzymes and SIF + enzymes. The aim of these experiments were to understand if the systems suffer any physicochemical or structural modification under these different conditions.

\subsection{Physicochemical and structural characterization of protein-CLA inclusion complexes}

2.5.1. Determination of particle size and $\zeta$ potential. Particle size distribution (PSD), polydispersivity index (PdI) and $\zeta$ potential for systems were determined by DLS at $25^{\circ} \mathrm{C}$, using a Zeta-Sizer (Nano-ZS 90, Malvern Instruments Ltd, United Kingdom) equipped with a light source at a wavelength of $632.8 \mathrm{~nm}$ and at $90^{\circ}$ scattering angle. Particle diameter was obtained from the peak of the Intensity (\%) vs. diameter (nm) curve (PSDi). PSD in volume (\%, PSDv) was also considered in particle diameter analysis.

2.5.2. Confocal laser scanning microscopy. Rhodamine B was used to stain the protein-CLA inclusion complexes. For this purpose, rhodamine B $(0.2 \% \mathrm{w} / \mathrm{v})$ solution was prepared and it was mixed with inclusion complexes solutions at $\mathrm{pH}$ 7.0. These samples were transferred onto a microscope slide, and they were covered with a cover slip. Images were taken by using an inverted microscope (Leica TCS SP8, Germany). The objective used was $63 \times / \mathrm{NA1}$.2/Water immersion lens. Excitation wavelength for rhodamine B was $514 \mathrm{~nm}$. For processing images, Fiji software was applied. ${ }^{24}$ 
2.5.3. Determination of encapsulation efficiency. In order to quantify CLA amount not bound to nanoparticles (free CLA), OVA nanoparticles (with loaded CLA) were precipitated by adjusting the $\mathrm{pH}$ at 4.8 (OVA isoelectric point) using $\mathrm{HCl} 1$ M. ${ }^{25}$ Then, a centrifugation step at $10000 \mathrm{~g}$ for $20 \mathrm{~min}$ was applied. In order to extract free CLA, supernatants were transferred to a clean falcon tubes, and they were mixed $1 \mathrm{~min}$ in a vortex with $1 \mathrm{ml}$ hexane. Then, a centrifugation step at $10000 \mathrm{~g}$ for $15 \mathrm{~min}$ was applied, and $0.5 \mathrm{ml}$ hexane phase was evaporated under $\mathrm{N}_{2}$ stream. Methanol was added, and resultant solutions were injected into a chromatographer system consisting of model Prominence Serie 20A (Shimadzu, Japan) equipped with a manual injector model 7725i (Rheodyne, USA) and a photodiode array detector model SPD-M20A (Shimadzu, Japan). CLA content was quantified by RP-HPLC, using a A C18 (ODS) Symmetry300 ${ }^{\mathrm{TM}}$ column (Waters Corp., USA) of $250 \mathrm{~mm}$ length, $4.6 \mathrm{~mm}$ inner diameter, $5 \mu \mathrm{m}$ particle size and $30 \mathrm{~nm}$ pore size. RP-HPLC experimental conditions were defined according to Sponton et al.; ${ }^{18} \mathrm{Li}$ et al. $^{26}$ and Murru et $a .^{27}$ Separation was performed by means of a linear gradient from $30 \%$ water $/ 70 \%$ acetonitrile (phase A) to $100 \%$ acetonitrile (phase B) over 15 min. Subsequently, 100\% acetonitrile was maintained over $5 \mathrm{~min}$. Acetic acid solution (0.12 vol\%) was added to both mobile phases, so as to adjust the $\mathrm{pH}$ and to prevent the ion exchange side effect. In all runs, solvent flow rate

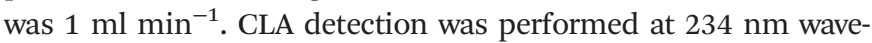
length due to the conjugated diene absorption. ${ }^{28}$ A calibration curve for CLA standard in methanol solution $\left(0-150 \mathrm{mg} \mathrm{L}^{-1}\right)$ was done. From the calibration curve, free CLA concentration were obtained, and CLA encapsulation efficiency in inclusion complexes ( $\mathrm{EE}_{\mathrm{CLA}}$ ) was calculated as the ratio between CLA encapsulated amount (in the nanoparticles) and CLA total amount,

$$
\mathrm{EE}_{\mathrm{CLA}}=\frac{\mathrm{CLA}_{\mathrm{T}}-\mathrm{CLA}_{\mathrm{f}}}{\mathrm{CLA}_{\mathrm{T}}} \times 100 \%
$$

where $\mathrm{CLA}_{\mathrm{T}}$ is the used amount for the formation of nanocomplexes, and CLA $_{f}$ is free CLA amount in the aqueous phase after encapsulation.

\subsection{Simulated gastrointestinal digestion of protein-CLA complexes and its characterization}

2.6.1. Enzymes activity. Pepsin activity was determined as described by Anson and Mirsky ${ }^{29}$ and Anson. ${ }^{30}$ Briefly, $1 \mathrm{ml}$ of haemoglobin was added into a tube, and it was incubated at $37{ }^{\circ} \mathrm{C}$ over $3-4 \mathrm{~min}$. Then, $200 \mu \mathrm{l}$ of pepsin solution, for each tested concentration, was added and it was incubated at $37{ }^{\circ} \mathrm{C}$ for $10 \mathrm{~min}$. To stop the reaction, $2 \mathrm{ml}$ of 5\% TCA was added into each tube. To obtain a clear solution, tubes were centrifuged at $6000 \mathrm{~g}$ over $30 \mathrm{~min}$. The aqueous phase was transferred to a clean tube, and it was stabilized at $20{ }^{\circ} \mathrm{C}$ for few minutes. Finally, the aqueous phase absorbance was measured at $280 \mathrm{~nm}$ and at $20{ }^{\circ} \mathrm{C}$. Blank tubes with the same procedure were made but adding pepsin (at each tested concentration) after 5\% TCA treatment. According to this, pepsin activity was $380 \pm 14 \mathrm{U} \mathrm{mg}^{-1}$.

Trypsin activity of pancreatin was measured as described by Hummel. ${ }^{31}$ Briefly, spectrophotometer was previously set at
$247 \mathrm{~nm}$ and at $25^{\circ} \mathrm{C}$. Then, $2.6 \mathrm{ml}$ of $46 \mathrm{mM}$ TRIS/HCl buffer containing $11.5 \mathrm{mM} \mathrm{CaCl}_{2}$ and $0.3 \mathrm{ml}$ of TAME were directly added into the measure cuvette, and this one was incubated at $25{ }^{\circ} \mathrm{C}$ during 3-4 min. Then, $100 \mu \mathrm{l}$ of pancreatin, for each tested concentration, was added. Absorbance at $247 \mathrm{~nm}$ and at $25^{\circ} \mathrm{C}$ was measured for $10 \mathrm{~min}$. The initial slope from the linear part of the curve was determined. A blank tube with the same protocol, but without pancreatin was also realized. Trypsin activity for pancreatin was $6.9 \pm 0.8 \mathrm{U} \mathrm{mg}^{-1}$.

2.6.2. Simulated gastrointestinal digestion assay. A simulation of gastrointestinal process, consisting of in vitro gastric and intestinal phases, based on an international consensus method, ${ }^{22}$ was carried out.

Gastric phase: In this phase, obtained inclusion complexes were mixed with an equal volume of simulated gastric fluid $1 \times$ (SGF $1 \times$ ) in two glass tubes with screw caps. SGF $1.25 \times$ was pre-

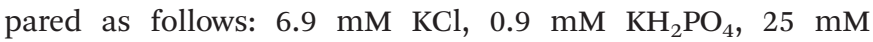
$\mathrm{NaHCO}_{3}, 47.2 \mathrm{mM} \mathrm{NaCl}, 0.1 \mathrm{mM} \mathrm{MgCl} 2,0.5 \mathrm{mM}\left(\mathrm{NH}_{4}\right)_{2} \mathrm{CO}_{3}$. Then, a volume of $0.3 \mathrm{M} \mathrm{CaCl}_{2}$ was added to obtain a final concentration of $0.075 \mathrm{mM} \mathrm{CaCl}_{2}$. Afterwards, $\mathrm{HCl}$ was used to adjust the $\mathrm{pH}$ at 3.0 , then pepsin solution $\left(2000 \mathrm{U} \mathrm{ml}^{-1}\right)$ and necessary quantity of water was added to obtain $1 \times$ SGF. The tubes were incubated at $37^{\circ} \mathrm{C}$ over $2 \mathrm{~h}$ under orbital agitation at $60 \mathrm{rpm}$ (Rotator Multi Bio RS-24, BOECO). Once the reaction was finished, one of the two tubes continued to the next phase, while for the other, $2 \mathrm{mM}$ protease inhibitor cocktail was added.

Intestinal phase: After the gastric phase took place, an equal volume of simulated intestinal fluid $1 \times($ SIF $1 \times)$ was added to the reaction tube. SIF $1.25 \times$ was prepared as follows: $6.8 \mathrm{mM}$ $\mathrm{KCl}, 0.8 \mathrm{mM} \mathrm{KH} \mathrm{KH}_{4}, 85 \mathrm{mM} \mathrm{NaHCO} 3,38.4 \mathrm{mM} \mathrm{NaCl}$, $0.33 \mathrm{mM} \mathrm{MgCl}$. Then, $\mathrm{CaCl}_{2}$ to reach a final concentration of $0.3 \mathrm{mM}$, and a solution of bile salts to reach a final concentration of $10 \mathrm{mM}$ were added. Afterwards, pancreatin solution previously dissolved in SIF $1.25 \times\left(100 \mathrm{U} \mathrm{ml}^{-1}\right.$ based on trypsin activity) and necessary quantity of water to obtain SIF $1 \times$ were added. After enzyme addition, a spin was performed at $4{ }^{\circ} \mathrm{C}$ to precipitate the insoluble material. Finally, the $\mathrm{pH}$ was adjusted to 7.0. The tubes were incubated at $37{ }^{\circ} \mathrm{C}$ for $2 \mathrm{~h}$ under orbital agitation at $60 \mathrm{rpm}$ (Rotator Multi Bio RS-24, BOECO). Once the reaction was finished, $2 \mathrm{mM}$ of protease inhibitor cocktail was added.

2.6.3. Determination of CLA retention. Samples of in vitro gastric and intestinal phases were taken to quantify released CLA. For this, the extraction and RP-HPLC methods described in 2.5.3 section were used. From the calibration curve, amount of released CLA was obtained. Subsequently, the CLA retention $\left(R_{\mathrm{CLA}}\right)$ in inclusion nanocomplexes after gastric and intestinal phases was calculated as follows:

$$
R_{\mathrm{CLA}}=\frac{\mathrm{CLA}_{\mathrm{e}}-\mathrm{CLA}_{\mathrm{r}}}{\mathrm{CLA}_{\mathrm{e}}} \times 100 \%
$$

where $\mathrm{CLA}_{\mathrm{e}}$ is the encapsulated CLA amount in nanocomplexes, and $\mathrm{CLA}_{\mathrm{r}}$ is the released CLA amount from the nanocomplexes after in vitro gastrointestinal digestion. 
2.6.4. Measurement of released soluble peptides. After in vitro gastrointestinal digestion, the solutions were adjusted to $\mathrm{pH} 4.8$ to precipitate nanocomplexes and, subsequently, samples were centrifuged at $10000 \mathrm{~g}$ for $20 \mathrm{~min}$. The amount of soluble peptides in supernatant was measured at $280 \mathrm{~nm}$ by using a UV visible spectrophotometer (Jenway 7305, UK). ${ }^{32}$ For this experiment, SGF $1 \times$ and SIF $1 \times$ were used as blanks.

2.6.5. Confocal laser scanning microscopy. Rhodamine B was used to stain the inclusion nanocomplexes previous to the in vitro gastrointestinal digestion procedure. ${ }^{33}$ Experiment were conducted as it was described in 2.5.2 section.

\subsection{Statistical analysis}

All assays were performed in triplicate at room temperature, unless otherwise stated. Means and standard deviations were calculated from these measurements. Differences between means were determined according to LSD test at 95\% significance level $(p<0.05)$ by using Stat Graphics Centurion XV software.

\section{Results and discussion}

\subsection{Physicochemical and structural characterization of protein-CLA inclusion complexes}

3.1.1. Size and $\zeta$ potential. It is known that heat treatment induces the formation of OVA aggregates, which show conformational characteristics dependent on the process conditions, such as $\mathrm{pH}$, temperature and ionic strength. ${ }^{34,35}$ Moreover, it was documented that the formation of disulphide bonds and hydrophobic interactions are relevant for aggregates formation. ${ }^{36,37}$

Colloidal behavior of inclusion nanocomplexes under in vitro gastrointestinal digestion constitutes an essential knowledge to formulate new functional foods. ${ }^{38,39}$ In this sense, digestion occurs mainly in stomach (gastric phase) at mean $\mathrm{pH}$ of 3.0 and in small intestine at mean $\mathrm{pH}$ of 7.0. So, the effect of $\mathrm{pH}$ (3.0 and 7.0) and CLA binding on size and electrical properties of OVA, $\mathrm{OVA}_{\mathrm{n} 1}$ and $\mathrm{OVA}_{\mathrm{n} 2}$ are presented in Fig. 1 and Table 1. Fig. 1 shows the PSDi for OVA and OVA-CLA at $\mathrm{pH} 7.0$ (A) and at $\mathrm{pH} 3.0(\mathrm{~B})$; for $\mathrm{OVA}_{\mathrm{n} 1}$ and $\mathrm{OVA}_{\mathrm{n} 1}$-CLA at $\mathrm{pH}$ 7.0 (C) and at pH 3.0 (D) and for $\mathrm{OVA}_{\mathrm{n} 2}$ and $\mathrm{OVA}_{\mathrm{n} 2}$-CLA at $\mathrm{pH}$ 7.0 (E) and at pH 3.0 (F). As it can be deduced from Table 1, at pH 7.0, CLA formed supramolecular structures with hydrodynamic diameter $\left(d_{\mathrm{H}}\right)$ of $289 \pm 3 \mathrm{~nm}(99.5 \pm 0.7 \%$ in volume $)$ and $\zeta$ potential of $-57 \pm 9 \mathrm{mV}$, indicating the formation of CLA stable colloidal suspensions. Nevertheless, at pH 3.0, there was a considerable increase in $d_{\mathrm{H}}, 2117 \pm 201 \mathrm{~nm}$. This could be explained considering that $\mathrm{pH} 3.0$ is close to $\mathrm{p} K_{\mathrm{a}}$ of carboxylic group of fatty acids and, therefore, the charge and electrostatic repulsions could decrease, allowing the formation of larger structures. This explanation is in agreement with $\zeta$ potential value found of $0 \pm 1 \mathrm{mV}$. It is important to mention that after $24 \mathrm{~h}$ no precipitates were observed, indicating that CLA supramolecular structures formed at $\mathrm{pH} 7.0$ and 3.0 were colloidally stable. When PUFA concentration exceeds a critical value in aqueous solution, known as critical micelle concentration
(CMC), fatty acids usually self-assemble to form supramolecular structures (e.g. micelles and vesicles), which confer turbidity to the solution. ${ }^{8,40,41}$ This phenomenon occurs because fatty acid molecules associate with tails arrange to each other inner while heads remain outside in contact with water molecules, so the particle size is in the same order of light wavelength. ${ }^{42}$

DLS measurements for OVA presented two peaks in PSDi (also in PSDv), both at pH 7.0 and 3.0 (Fig. 1). The first peak at $12 \pm 2 \mathrm{~nm}(97.5 \%)$ and at $10.3 \pm 0.4 \mathrm{~nm}(97 \%)$, and the second one at $62 \pm 3 \mathrm{~nm}(2.5 \%)$ and at $58 \pm 3 \mathrm{~nm}$ (3\%), respectively. Kang et $a{ }^{43}{ }^{43}$ reported that no conformational changes in the second and tertiary OVA structure were registered under $\mathrm{pH}$ changes. Hence, in general terms, it could conclude that the first peaks observed for both $\mathrm{pH}$ values (7.0 and 3.0) would correspond to OVA $d_{\mathrm{H}}$, and the second ones to traces of some aggregated protein. Nevertheless, at pH 7.0, OVA-CLA complexes showed two main peaks: at $93 \pm 18 \mathrm{~nm}(44 \%)$ and at $288 \pm 8 \mathrm{~nm}(55 \%)$ (Table 1; Fig. 1A). So, it could be deduced that smaller peak corresponds to the formation of inclusion complexes based on CLA and OVA, and larger one to CLA supramolecular structures (i.e. CLA not bound to native protein). The OVA $\zeta$ potential value was $-15 \pm 2 \mathrm{mV}$, due to the negative charge of carboxyl groups, whereas the complex formation caused a decrease in $\zeta$ potential to $-26 \pm 2 \mathrm{mV}$. The decrease in $\zeta$ potential value could be explained by the formation of inclusion nanocomplexes. The $\zeta$ potential can be modified by the adsorption of charged species such as ions and ionic surfactants on particle surface. ${ }^{44}$ CLA molecules have an aliphatic chain (apolar tail) at one end and a carboxylic group (polar head) at the other. Therefore, if CLA is bound to OVA through hydrophobic interactions by means of its aliphatic chain, the ionized polar head would be oriented outside onto the protein surface in contact with aqueous medium increasing the negative charge of OVA. ${ }^{20}$

In addition, PSDi for OVA-CLA nanocomplex at $\mathrm{pH}$ 3.0, was similar to the one observed at $\mathrm{pH} 7.0$, showing two peaks: at $44 \pm 4 \mathrm{~nm}(23 \%)$ and at $207 \pm 14 \mathrm{~nm}$ (75\%) (Table 1; Fig. 1B). The $\zeta$ potential for OVA at $\mathrm{pH} 3.0$ was $19 \pm 1 \mathrm{mV}$, due to the presence of protonated amino groups on the protein, while for OVA-CLA nanocomplex was $10.0 \pm 0.5 \mathrm{mV}$. This could be explained considering that CLA had a slight negative charge, and under binding to OVA, the nanocomplex $\zeta$ potential decreased.

For $\mathrm{OVA}_{\mathrm{n} 1}$ at $\mathrm{pH} 7.0, d_{\mathrm{H}}$ was $24.63 \pm 0.04 \mathrm{~nm}(100 \%)$, while for $\mathrm{OVA}_{\mathrm{n} 1}$-CLA inclusion complex two peaks were registered: at $28.79 \pm 0.05(99.8 \%)$ and at $224 \pm 24(0.2 \%) \mathrm{nm}$ (Table 1; Fig. 1C). As it can be noted, the binding of CLA produced an increase in $\mathrm{OVA}_{\mathrm{n} 1}$ size $(p<0.05)$, and almost all the nanoparticles volume would correspond to the presence of nanocomplexes, so the amount of free PUFA could be negligible. The $\zeta$ potential value for $\mathrm{OVA}_{\mathrm{n} 1}$ was $-15.9 \pm 0.1 \mathrm{mV}$. Complexation between $\mathrm{OVA}_{\mathrm{n} 1}$ and CLA produced a decrease of $\zeta$ potential value to $-28 \pm 1 \mathrm{mV}$. These results were consistent with the ones obtained for OVA-CLA inclusion complex.

At pH 3.0, PSDi and PSDv for OVA 1 showed a $d_{\mathrm{H}}$ of $23.1 \pm$ $0.8 \mathrm{~nm}(100 \%)$ and no significant difference $(p>0.05)$ in comparison with $\mathrm{pH} 7.0$ was found. Meanwhile for the $\mathrm{OVA}_{\mathrm{n} 1}-\mathrm{CLA}$ 

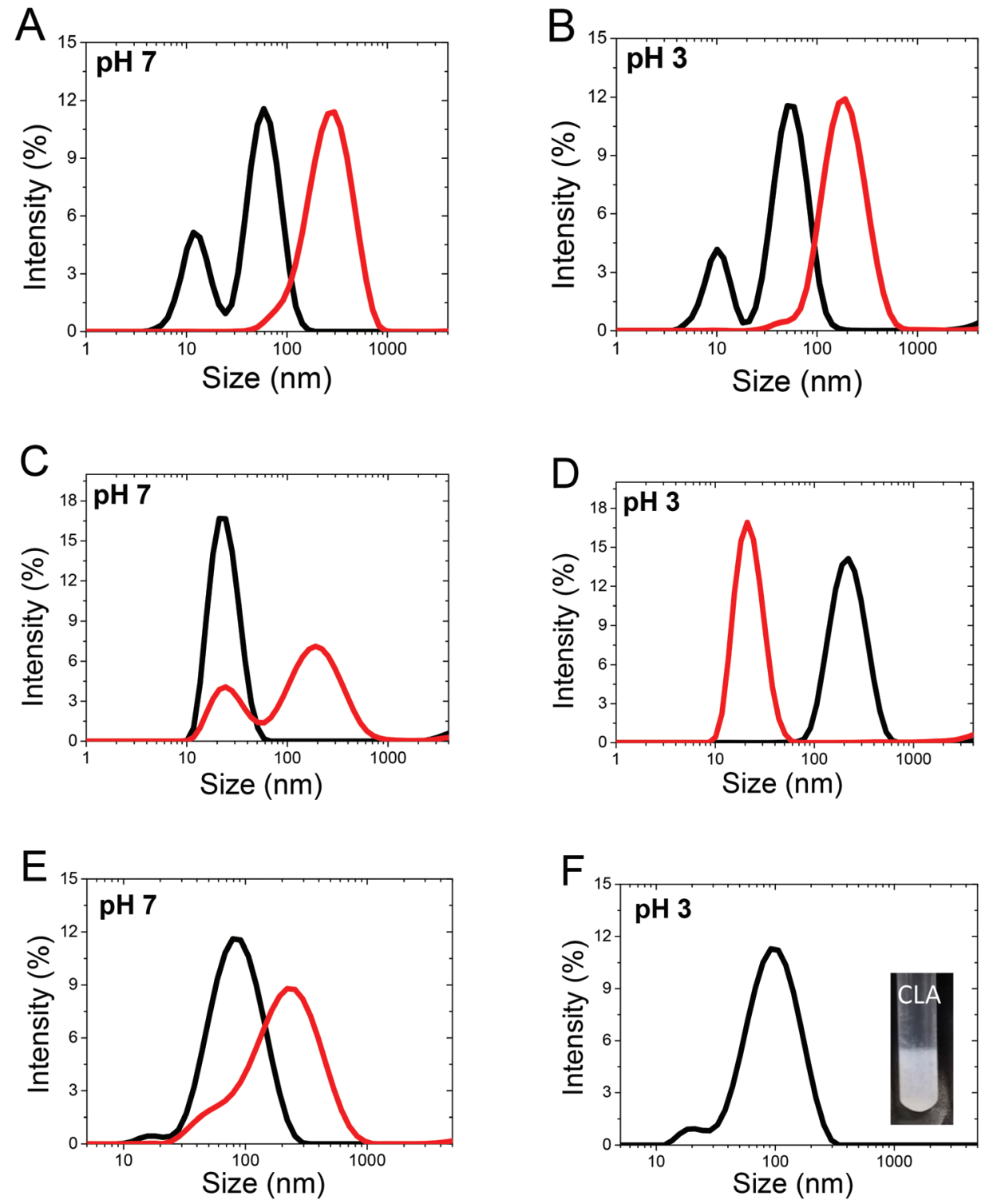

Fig. 1 Particle size distribution (PSD) based on Intensity percentage (\%) for OVA (-), OVA-CLA (-) at pH $7.0(A)$ and pH $3.0(B)$; OVA $A_{n 1}(-)$, OVA $A_{n 1}$-CLA $(-)$ at pH 7.0 (C) and pH 3.0 (D) and $\mathrm{OVA}_{\mathrm{n} 2}(-), \mathrm{OVA}_{\mathrm{n} 2}-\mathrm{CLA}(-)$ at $\mathrm{pH} 7.0$ (E) and pH 3.0 (F; the tube photo shows the aspect of OVA $\mathrm{n}-\mathrm{CLA}$ precipitate). Conditions: Protein concentration: $23 \mu \mathrm{M}$, PUFA concentration: $1 \mathrm{mM}$, temperature: $25^{\circ} \mathrm{C}$.

nanocomplex, only one peak was detected at $231 \pm 2 \mathrm{~nm}$ (100\%) (Table 1; Fig. 1D). In addition, OVA $_{n 1}$-CLA nanocomplex solution presented a slight turbidity, which could be due to the nanocomplex size is in the order of light wavelength. ${ }^{42}$ $\mathrm{OVA}_{\mathrm{n} 1}$ had a $\zeta$ potential value of $15.2 \pm 0.6 \mathrm{mV}$, whereas the $\mathrm{OVA}_{\mathrm{n} 1}$-CLA nanocomplex formation produced an increase in the $\zeta$ potential value to $26 \pm 1 \mathrm{mV}$.

For $\mathrm{OVA}_{\mathrm{n} 2}$ at $\mathrm{pH} 7.0$, two peaks at $92.0 \pm 0.2 \mathrm{~nm}(98.2 \%)$ and at $16 \pm 2 \mathrm{~nm}(1.7 \%)$ were registered, being the first one representative of the protein nanoparticle. In addition, for $\mathrm{OVA}_{\mathrm{n} 2}$-CLA complex, also two peaks appeared at $237 \pm 43 \mathrm{~nm}$ $(83 \%)$ and at $31 \pm 20 \mathrm{~nm}(16 \%)$ (Table 1; Fig. 1E). The binding of CLA produced an increase in $\mathrm{OVA}_{\mathrm{n} 2}$ size indicating the nanocomplex formation. The $\zeta$ potential value for this nano- particle was $-15 \pm 2 \mathrm{mV}$, and for $\mathrm{OVA}_{\mathrm{n} 2}$-CLA nanocomplex was $-19.4 \pm 0.3 \mathrm{mV}$.

At pH 3.0, the $\mathrm{OVA}_{\mathrm{n} 2}$ had a $d_{\mathrm{H}}$ of $103 \pm 1 \mathrm{~nm}$ (98\%) (Table 1; Fig. 1F), and no significant difference with $\mathrm{pH} 7.0$ was found $(p>0.05)$. Nevertheless, the $d_{\mathrm{H}}$ for $\mathrm{OVA}_{\mathrm{n} 2}$-CLA system cannot be determined due to the precipitate formation (Insert in Fig. 1F). This phenomenon might be due to the formation of big nanocomplex aggregates that precipitate as a consequence of gravitational force. The $\zeta$ potential value for $\mathrm{OVA}_{\mathrm{n} 2}$ and OVA $_{n 2}$-CLA nanocomplex were $14.7 \pm 0.3 \mathrm{mV}$ and $13.9 \pm$ $0.4 \mathrm{mV}$, respectively, indicating that $\mathrm{pH} 3.0$ had no influence on the $\zeta$ potential values $(p>0.05)$.

In summary, $\zeta$ potentials values did not show significant differences $(p>0.05)$ for OVA and OVA nanoparticles at $\mathrm{pH} 7.0$, 
Table 1 Effect of protein-CLA complexation on hydrodynamic diameter $(\mathrm{nm})$, volume $(\%)$ and zeta potential $(\zeta, \mathrm{mV})$ of OVA, OVA $\mathrm{n}_{1}$ and $\mathrm{OVA}_{\mathrm{n} 2}$ as a function of aqueous medium pH. Conditions: Protein concentration: $23 \mu \mathrm{M}$, CLA concentration: $1 \mathrm{mM}$, temperature: $25^{\circ} \mathrm{C}$. The ANOVA for hydrodynamic diameter was performed for each system (e.g. OVA and OVA-CLA at pH 7.0 and 3.0). The ANOVA for $\zeta$ potential was made for all systems together. Values are showed as mean \pm standard deviation and different letters indicate statistical differences $(p<0.05)$

\begin{tabular}{lllll}
\hline System & pH & Diameter $(\mathrm{nm})$ & Volume $(\%)$ & Zeta potential $(\mathrm{mV})$ \\
\hline CLA & 7 & $289 \pm 3^{\mathrm{a}}$ & $99.5 \pm 0.7$ & $-57 \pm 9^{\mathrm{a}}$ \\
& 3 & $2117 \pm 201^{\mathrm{b}}$ & 100 & $0 \pm 1^{\mathrm{e}}$ \\
OVA & 7 & $12 \pm 2^{\mathrm{a}}$ & $97.5 \pm 0.4$ & $-15 \pm 2^{\mathrm{d}}$ \\
& & $62 \pm 3^{\mathrm{c}}$ & $2.5 \pm 0.4$ & \\
& 3 & $10.3 \pm 0.4^{\mathrm{a}}$ & $97.15 \pm 0.07$ & $19 \pm 1^{\mathrm{h}}$ \\
OVA-CLA & 7 & $93 \pm 3^{\mathrm{c}}$ & $2.85 \pm 0.07$ & \\
& & $288 \pm 8^{\mathrm{f}}$ & $44 \pm 11$ & $-26 \pm 2^{\mathrm{b}}$ \\
& 3 & $44 \pm 4^{\mathrm{b}}$ & $55 \pm 11$ & \\
OVA $_{\mathrm{n} 1}$ & 7 & $24.63 \pm 0.04^{\mathrm{a}}$ & $74.9 \pm 0.4$ & $100.0 \pm 0.5^{\mathrm{f}}$ \\
OVA $_{\mathrm{n} 1}$-CLA & 3 & $23.1 \pm 0.8^{\mathrm{a}}$ & 100 & $-15.9 \pm 0.1^{\mathrm{d}}$ \\
& 7 & $28.79 \pm 0.05^{\mathrm{b}}$ & $99.8 \pm 0.07$ & $-28 \pm 1^{\mathrm{b}}$ \\
& 3 & $224 \pm 24^{\mathrm{c}}$ & $0.2 \pm 0.07$ & \\
OVA $_{\mathrm{n} 2}$ & 7 & $92.0 \pm 0.2^{\mathrm{b}}$ & 100 & $26.2 \pm 1.5^{\mathrm{i}}$ \\
& & $16 \pm 2^{\mathrm{a}}$ & $1.7 \pm 0.9$ & $-15 \pm 2^{\mathrm{d}}$ \\
& 3 & $103 \pm 1^{\mathrm{b}}$ & $98 \pm 2$ & $14.7 \pm 0.3^{\mathrm{g}}$ \\
OVA $_{\mathrm{n} 2}$-CLA & 7 & $21.22 \pm 2^{\mathrm{a}}$ & $2 \pm 2$ & \\
& & $31 \pm 23^{\mathrm{c}}$ & $83 \pm 5$ & $-19.4 \pm 0.3^{\mathrm{c}}$ \\
& 3 & Precipitation & $16 \pm 5$ & \\
& & & &
\end{tabular}

and they were statistically similar at $\mathrm{pH}$ 3.0, suggesting that heat treatment and $\mathrm{pH}$ had little influence on the protein net charge. In the same way, there were not significant differences among the sizes of OVA, OVA 1 and $\mathrm{OVA}_{\mathrm{n} 2}$ both at pH 3.0 and at $\mathrm{pH}$ 7.0. On the other hand, the increase in particle size for all systems with CLA indicated the formation of protein-CLA inclusion nanocomplexes.

3.1.2. Confocal laser scanning microscopy. Fig. 2 shows CSLM for OVA-CLA (A), OVA ${ }_{n 1}$-CLA (B) and OVA $_{n 2}$-CLA (C) stained with rhodamine $\mathrm{B}$. For the three nanocomplexes, a circular shape was observed and the sizes were in agreement with the ones reported in previous section. Firstly, for OVA-CLA nanocomplex (Fig. 2A), the size was very small and only one population could be identified. Nevertheless, for both nanoparticles, two populations could be seen: one corresponding to size around $25 \mathrm{~nm}$ for $\mathrm{OVA}_{\mathrm{n} 1}$-CLA system (Fig. 2B) or around to $90 \mathrm{~nm}$ for $\mathrm{OVA}_{\mathrm{n} 2}$-CLA system (Fig. 2C), and another population with minor size that could correspond to a fraction of not aggregated OVA. CLSM images indicated that OVA or OVA nanoparticles were evenly distributed throughout the colloidal solution samples, i.e., extensive particle aggregation was not evidenced (Fig. 2).

3.1.3. Encapsulation efficiency. The percentage of encapsulated (loaded) CLA ( $\mathrm{EE}_{\mathrm{CLA}}$ ) in OVA, OVA 1 and $\mathrm{OVA}_{\mathrm{n} 2}$ are shown in Fig. 3. Both nanoparticles had slightly higher $(p<0.05)$ $\mathrm{EE}_{\mathrm{CLA}}$ values than the one observed for OVA (99\% against $97 \%$, respectively). However, there was no significant differences in
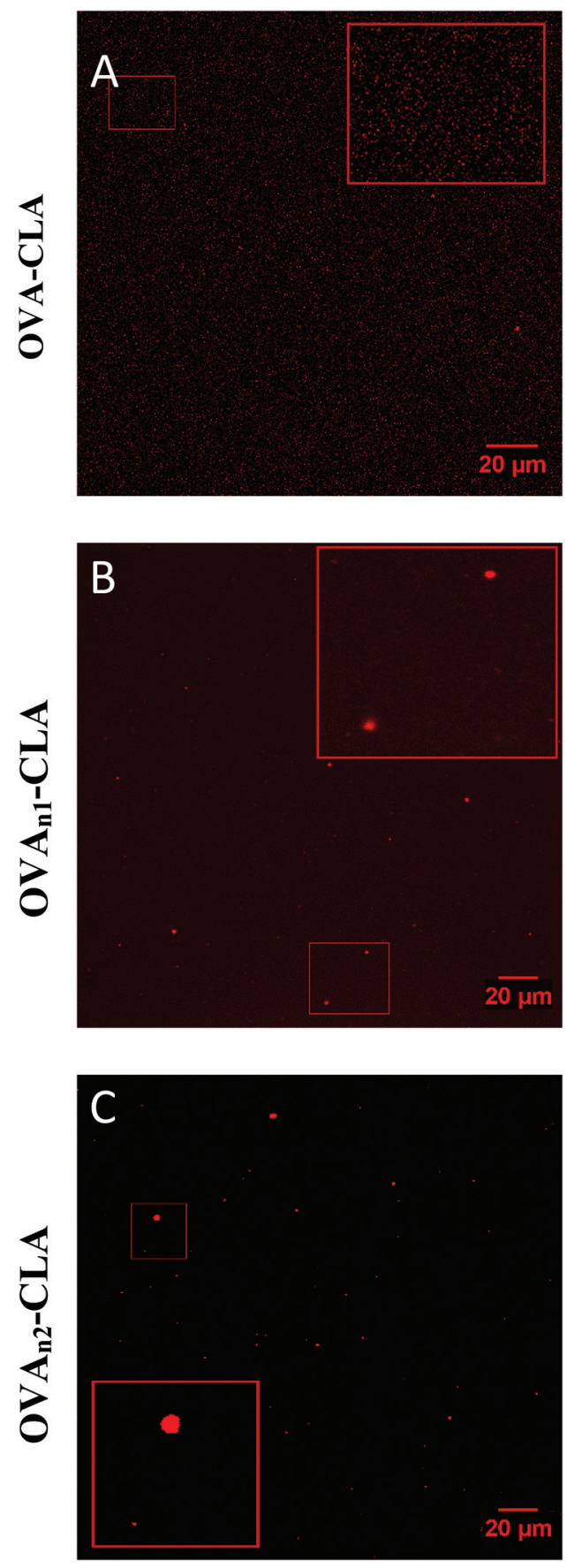

Fig. 2 Confocal laser scanning microscopy (CSLM) of OVA-CLA (A), $\mathrm{OVA}_{n 1}-\mathrm{CLA}(\mathrm{B})$ and $\mathrm{OVA}_{n 2}$-CLA (C) stained with rhodamine $B$. The thick border box shows a zoom of the thin border box (zoom factor: 3 ). Objective used was $63 x$.

$\mathrm{EE}_{\mathrm{CLA}}$ values between both nanoparticles ( $\left.p>0.05\right)$, highlighting that particle size had no influence on encapsulated CLA.

\subsection{In vitro gastrointestinal digestion of OVA-CLA inclusion complexes and their characterization}

3.2.1. Macroscopic appearance. Fig. 4 shows the macroscopic appearance of OVA-CLA, OVA ${ }_{n 1}$-CLA and $\mathrm{OVA}_{\mathrm{n} 2}$-CLA 


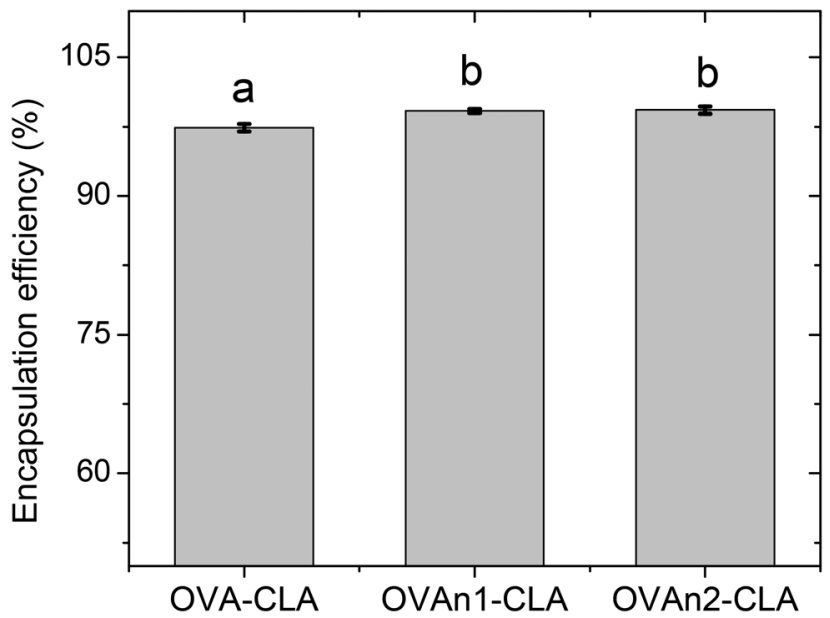

Fig. 3 Encapsulation efficiency of CLA (\%) for OVA, OVA $A_{n 1}$ and $O V A_{n 2}$, expressed as percentage. Different letters indicate statistical differences.

nanocomplexes under in vitro gastrointestinal digestion. In first place, the systems were assayed to gastric and intestinal phases, but only with SGF (without pepsin) and SIF (without pancreatin and bile salts) for $2 \mathrm{~h}$ at $37^{\circ} \mathrm{C}$ under orbital agitation at corresponding pHs (i.e. 3 and 7). The aim of this assay was to study the influence of $\mathrm{pH}$ and salt composition of simu- lated fluids on visual aspects and CLA retention of inclusion nanocomplexes. As it can be seen, systems presented turbidity and the presence of small particles both, in SGF and SIF for OVA-CLA, OVA ${ }_{n 1}-$ CLA and $\mathrm{OVA}_{\mathrm{n} 2}$-CLA systems. In order to understand what happened, it is necessary to analyze the variables of the in vitro digestion protocol such as agitation, temperature and presence of salts. All solutions were subjected to orbital agitation at $60 \mathrm{rpm}$, heat at $37{ }^{\circ} \mathrm{C}$ and salts addition (as $\mathrm{CaCl}_{2}$ ) over $2 \mathrm{~h}$. It is known that proteins denature and aggregate by shaking, and OVA is very sensible to agitation. ${ }^{45-47}$ In addition, there is evidence that $\mathrm{Ca}^{2+}\left(\right.$ as $\left.\mathrm{CaCl}_{2}\right)$ accelerate proteins aggregation, in general, ${ }^{48,49}$ and the OVA one, in particular. ${ }^{50}$ Cheng et al. ${ }^{51}$ studied digestion of zein nanoparticles and when they were subjected to SGF, a precipitation phenomenon was observed. Authors explained that added ions increased both the amount of non-dispersed protein and the tendency of particles to self-assemble into larger structures. Although for most of nanoparticles, the conditions used were more extreme than those used in the in vitro digestion protocol, the combination of all factors for a prolonged period were applied in this assay. This combination could explain the macroscopic appearance of aggregates in the systems, when they were subjected to SGF. In SIF, small particles in suspensions and less turbidity were evidenced, which could suggest that aggregates formed under gastric conditions remained

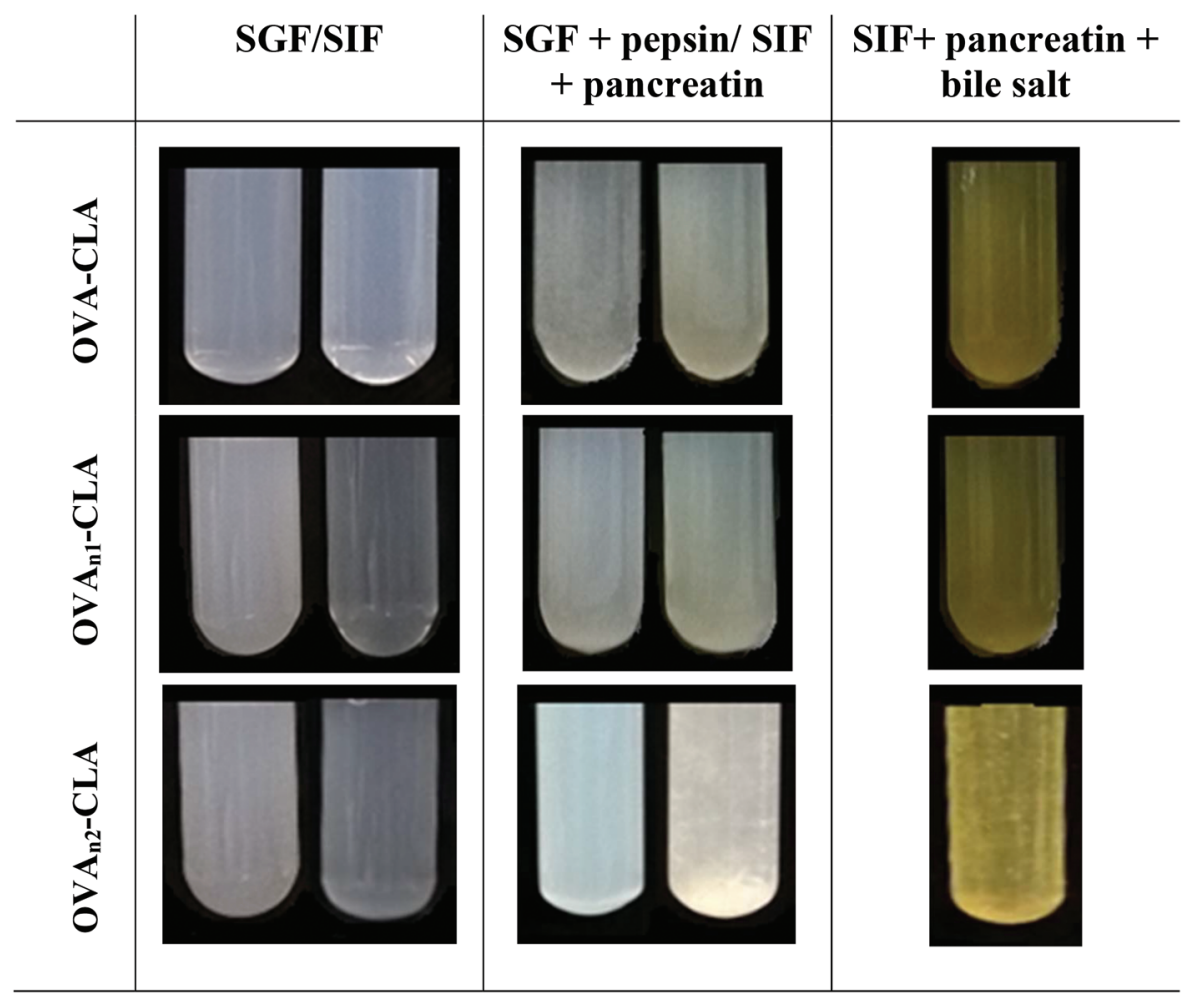

Fig. 4 Photographs of the macroscopic appearance of the different systems (OVA-CLA, OVA ${ }_{n 1}-C L A$ and OVA $\left.{ }_{n 2}-C L A\right)$ when they are subjected to an in vitro gastrointestinal digestion. SGF/SIF column: the systems were subjected to an in vitro digestion without enzymes. Left photo corresponds to gastric phase and right photo corresponds to intestinal phase. SGF + pepsin/SIF + pancreatin column: the systems were subjected to an in vitro digestion with enzymes. Left photo corresponds to gastric phase and right photo corresponds to intestinal phase. SIF + pancreatin + bile salt column: the systems were subjected to an in vitro digestion with enzymes and bile salt in the intestinal phase. 
intact in the intestine. It is necessary to mention that all the systems precipitated after a few hours resting.

In other assay, systems were subjected to in vitro digestion with enzymes. For SGF, pepsin was added at $2000 \mathrm{U} \mathrm{ml}^{-1}$ final activity, and for SIF, pancreatin was added at $100 \mathrm{U} \mathrm{ml}^{-1}$ (ref. 22) final activity. At the same time, so as to complete the in vitro model, systems were subjected to an intestinal phase under presence of pancreatin and bile salts. As it was noted before, all systems showed turbidity and small particles in suspension, both in gastric and intestinal phases. Particle sizes could not be determined due to the presence of nanoparticles precipitated in all systems. The presence of enzymes seemed to have no influence on macroscopic appearance.

In SGF + pepsin systems, the presence of particles in suspension could indicate that the aggregates formed under conditions discussed above were not hydrolyzed by pepsin, or if they were hydrolyzed, the resulting peptides could aggregate due to gastric conditions. Martos et al. ${ }^{52}$ studied OVA digestion and they discovered that it was very resistant to pepsin action at $\mathrm{pH}$ values around 2.0. OVA adopts a molten globule state maintaining a high degree of conformational stability and resisting pepsin action. The degree of enzymatic hydrolysis depends on heating conditions used during nanoparticles formation and on its morphology, since this might cause that the cleavage sites were more or less exposed to pepsin. ${ }^{53,54}$ On the other side, aggregation could protect OVA nanoparticles from enzymatic cleavage. In this sense, Del Castillo-Santaela et al. (2016) found that when human serum albumin is crosslinked with glutaraldehyde, the formation of large aggregates makes the system very resistant to pepsin action. ${ }^{54}$ Pepsin is a watersoluble enzyme and its activity is limited if peptide-substrates are not well dispersed in the media. ${ }^{51}$

In SIF + pancreatin systems, $\mathrm{OVA}_{\mathrm{n} 2}$-CLA system had greater turbidity and precipitated immediately, whereas OVA-CLA and $\mathrm{OVA}_{\mathrm{n} 1}$-CLA samples required more time to precipitate. In presence of bile salts, the behavior was the same, but a yellow color (own of bile salts) was observed. Nyemb et al. ${ }^{53}$ reported that only $37 \%$ of OVA resisted to pancreatin digestion, and only $30 \%$ of agglomerated OVA resisted intestinal digestion. Complementary studies would be required to determine if nanoparticles remain intact forming aggregates or if they break into peptides. In this sense, Chen et al. ${ }^{55}$ found that soy protein isolate nanoparticles loaded with curcumin formed aggregates when they were subjected to an in vitro gastrointestinal digestion. In SGF and SIF the nanoparticles aggregation was attributed to protein hydrolysis that could promote the exposure of protein hydrophobic clusters towards the aqueous phase, or the release of hydrophobic peptides able to promote aggregation.

3.2.2. CLA retention. The CLA retention $\left(R_{\mathrm{CLA}}\right)$ after in vitro gastrointestinal digestion was evaluated for OVA, OVA 1 and $\mathrm{OVA}_{\mathrm{n} 2}$ systems (Table 2). In first place, $R_{\mathrm{CLA}}$ was calculated for systems subjected to gastric phase without enzymes. As it could be observed, there was no significant differences among the $R_{\text {CLA }}$ for OVA and for both OVA nanoparticles $(p>0.05)$. When pepsin was added, the $R_{\mathrm{CLA}}$ decreased significantly ( $p<$ 0.05 ) respect to gastric phase without enzymes for OVA-CLA and $\mathrm{OVA}_{\mathrm{n} 2}$-CLA systems. The $R_{\mathrm{CLA}}$ values for $\mathrm{OVA}_{\mathrm{n} 1}$ and $\mathrm{OVA}_{\mathrm{n} 2}$ systems were high. These results were consistent with the presence of dispersed particles, since if proteins were not hydrolysed, they could retain most of the encapsulated CLA.

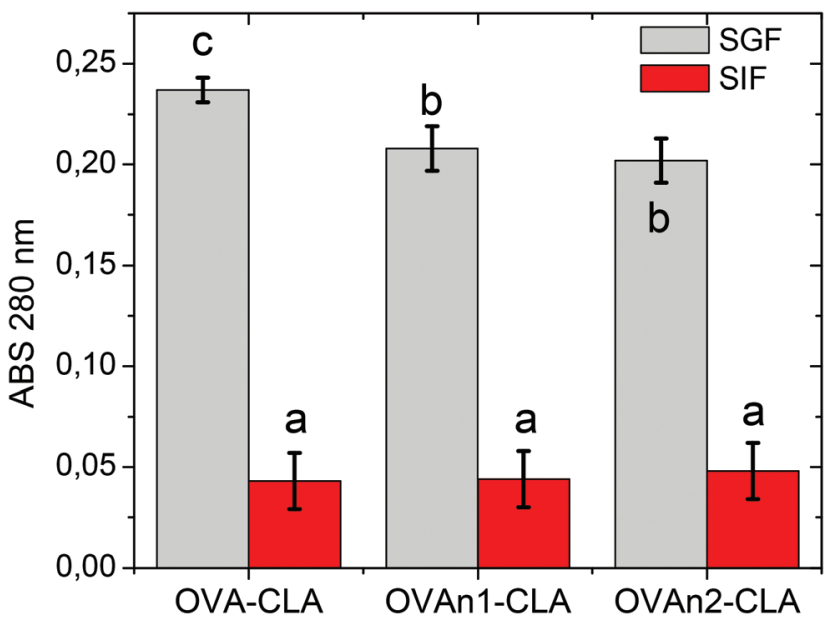

Fig. 5 Absorbance at $280 \mathrm{~nm}$ as a measure of released peptides from OVA-CLA, OVA ${ }_{n 1}-C L A$ and $O_{2 A}{ }_{n 2}-C L A$ after gastric ( , pepsin) or intestinal ( pancreatin and bile salts) in vitro digestion. Different letters indicate statistical differences.

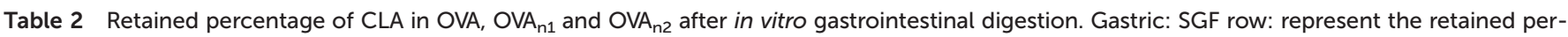

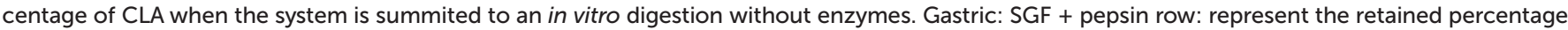

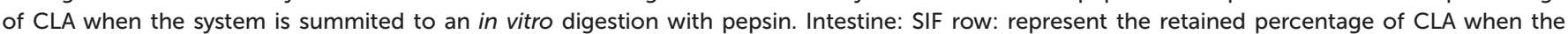

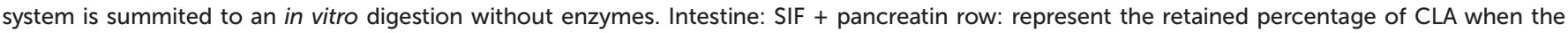

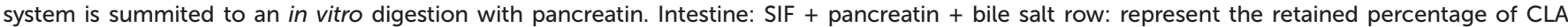
when the system is summited to an in vitro digestion with pancreatin and bile salt. Different letters indicate statistical differences ( $p<0.05$ )

\begin{tabular}{|c|c|c|c|}
\hline & \multicolumn{3}{|c|}{ Percentage of retained CLA (\%) } \\
\hline & OVA-CLA & $\mathrm{OVA}_{\mathrm{n} 1}$-CLA & $\mathrm{OVA}_{\mathrm{n} 2}-\mathrm{CLA}$ \\
\hline Gastric: SGF & $99.5 \pm 0.1^{\mathrm{c}}$ & $99.6 \pm 0.1^{\mathrm{c}}$ & $99.6 \pm 0.1^{\mathrm{c}}$ \\
\hline Gastric: SGF + pepsin & $82 \pm 2^{\mathrm{a}}$ & $98.9 \pm 0.2^{\mathrm{c}}$ & $96.2 \pm 0.7^{\mathrm{b}}$ \\
\hline Intestine: SIF & $99.4 \pm 0.1^{\mathrm{c}}$ & $99.5 \pm 0.1^{\mathrm{c}}$ & $99.5 \pm 0.1^{\mathrm{c}}$ \\
\hline Intestine: SIF + pancreatin & $99.5 \pm 0.1^{\mathrm{c}}$ & $98.7 \pm 0.2^{c}$ & $99.3 \pm 0.2^{\mathrm{c}}$ \\
\hline Intestine: SIF + pancreatin + bile salt & $99.3 \pm 0.2^{\mathrm{c}}$ & $99.3 \pm 0.2^{\mathrm{c}}$ & $99 \pm 1^{c}$ \\
\hline
\end{tabular}


Moreover, if hydrolysis occurs, possibly the resulting peptides could retain the ability to bind CLA. ${ }^{51}$ OVA retained CLA in minor proportion compared with both nanoparticles $(p<$ 0.05). Besides, $\mathrm{OVA}_{\mathrm{n} 1}$ retained slightly higher amount of CLA than $\mathrm{OVA}_{\mathrm{n} 2}$ sample $(p<0.05)$ after SGF.
After gastric phase, the systems were subjected to SIF phase without enzymes to evaluate how intestinal condition influenced on retained CLA. As it was discussed before, there were not statistical differences in $R_{\mathrm{CLA}}$ among OVA, OVA $\mathrm{n}_{1}$ and $\mathrm{OVA}_{\mathrm{n} 2}$ samples. In addition, these values were not different
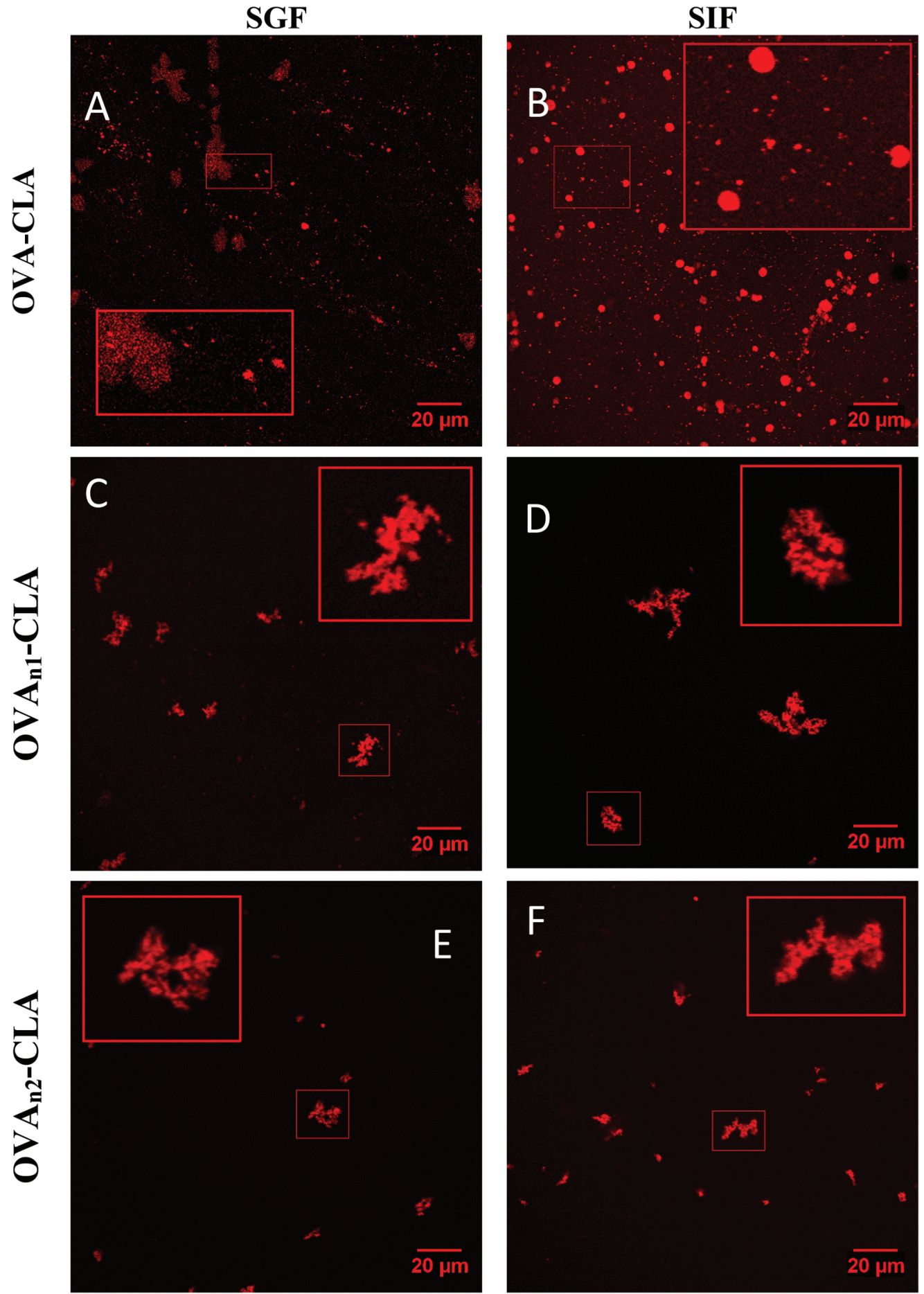

Fig. 6 Confocal Laser Scanning microscopy (CSLM) of OVA-CLA (A, B), OVA ${ }_{n 1}-C L A(C, D)$ and OVA $A_{n 2}-C L A(E, F)$ stained with rhodamine B after in vitro gastrointestinal digestion. SGF: systems were summited a simulated gastric fluid containing pepsin. SIF: systems were summited a simulated intestinal fluid containing pancreatin and bile salts. The thick border box shows a zoom of the thin border box (zoom factor: 3). Objective used: $63 x$. 
that the ones obtained for SGF without enzymes. This could suggest that protein aggregates formed under gastric condition remained intact after intestinal conditions. On the other hand, when systems were digested under SIF + pancreatin or SIF + pancreatin + bile salts, no statistical differences in $R_{\text {CLA }}$ among OVA, OVA $_{\mathrm{n} 1}$ or $\mathrm{OVA}_{\mathrm{n} 2}$ samples $(p>0.05)$ were found, and the values were around $99 \%$. The $R_{\mathrm{CLA}}$ values in intestinal phase were the same or superior (in the case of OVA) in comparison with gastric phase. This result could be explained assuming that the aggregates formed in the gastric phase at $\mathrm{pH} 3.0$ could remain intact, and the pancreatin in intestine could not be able to break them.

3.2.3. Released soluble peptides. In order to confirm previous results, peptides released from proteins after simulated digestion were spectroscopically determined by means of absorbance at $280 \mathrm{~nm}$ (Fig. 5). ${ }^{32}$ In SGF, the released peptides amount was higher than the ones registered in SIF for all systems. OVA-CLA system in SGF released a greater amount of peptides than when CLA is bound to both OVA nanoparticles $(p<0.05)$. These results could be explained considering that protein aggregation and further complexation with CLA might have promote enzymes cleavage sites occlusion. On the other hand, there was no significant difference in the released peptides amount for OVA or OVA nanoparticles in SIF $(p>0.05)$.

3.2.4. Confocal laser scanning microscopy. All systems were stained with rhodamine $\mathrm{B}$ and they were assayed by CSLM (Fig. 6). Images for OVA-CLA system in SGF + pepsin (Fig. 6A) showed big amorphous aggregates and others small and spherical structures. In SIF + pancreatin (Fig. 6B), it could be observed bigger spherical aggregates. For OVA ${ }_{n 1}$-CLA and OVA $_{n 2}$-CLA systems in SGF + pepsin (Fig. 6C and E, respectively) and in SIF + pancreatin (Fig. 6D and F, respectively) big amorphous aggregates were observed. These results are in agreement with the precipitation behavior (Fig. 4), that might be promoted by the observed aggregates. On the other side, it can be hypothesized that assembly of individual nanoparticles could form aggregates. This observation could confirm that nanoparticles aggregate at $\mathrm{pH} 3.0$ and did not dissolved or enzymes attacked them. CLA could be strongly retained in nanoparticles due to the formation of these big aggregates. As it was mentioned before, a complementary study would be required to confirm if the nanoparticles remain intact forming aggregates or if they break into peptides that subsequently aggregate.

\section{Conclusions}

In the present work, two nanoparticles and their CLA inclusion nanocomplexes were obtained and characterized in terms of particle size, electrical properties and morphological aspects. Complexation among OVA/OVA nanoparticles with CLA showed an increase in particle size, furthermore CLSM confirmed a rounded shape for inclusion nanocomplexes. The efficiency of OVA, $\mathrm{OVA}_{\mathrm{n} 1}$ and $\mathrm{OVA}_{\mathrm{n} 2}$ to encapsulate CLA were superior to
97\%. Finally, the nanocomplexes were subjected to an in vitro gastrointestinal digestion. Macroscopic appearance of all systems showed the presence of protein aggregates and dispersed particles which subsequently precipitated after a resting time. For all systems, CLSM images highlighted the presence of amorphous aggregates. For OVA and both nanoparticles, great CLA retention was obtained after enzyme digestion in gastric and intestinal phases. The results obtained in this paper would suggest that these inclusion nanocomplexes could be applied as promising oral delivery systems for CLA and other lipophilic drugs at gastrointestinal tract. The greater gastrointestinal retention showed by this system could be exploited in the design of new functional foods for prevention/ treatment of colon cancer. In a future contribution, this issue will be addressed.

\section{Conflicts of interest}

There are no conflicts to declare.

\section{Acknowledgements}

Authors acknowledge the financial support of the following projects: CAI+D-2013-50120110100-171-LI (UNL) and PICT-2014-2636 (ANPCyT), CONICET for the PhD fellowship awarded to Flavia F. Visentini and ANPCyT for fellowship awarded to Joana B. Ferrado.

\section{References}

1 H. S. Moon, H. G. Lee, C. S. Chung, Y. J. Choi and C. S. Cho, Physico-chemical modifications of conjugated linoleic acid for ruminal protection and oxidative stability, J. Nutr. Metab., 2008, 5-16.

2 M. A. De la Fuente, P. Luna and M. Juárez, Chromatographic techniques to determine conjugated linoleic acid isomers, Trends Anal. Chem., 2006, 25(9), 917-026.

3 N. S. Kelley, N. E. Hubbard and K. L. Erickson, Conjugated Linoleic Acid Isomers and Cancer, J. Nutr., 2007, 137(12), 2599-2607.

4 S. J. Hur, D. H. Kim, S. C. Chun and S. K. Lee, Effects of Dietary Conjugated Linoleic Acid and Biopolymer Encapsulation on Lipid Metabolism in Mice, Int. J. Mol. Sci., 2013, 14, 6848-6862.

5 D. Kritchevskya, S. A. Teppera, S. Wrighta, S. K. Czarneckib, T. A. Wilsonc and R. J. Nicolosi, Conjugated Linoleic Acid Isomer Effects in Atherosclerosis: Growth and Regression of Lesions, Lipids, 2004, 39, 611616.

6 A. Jaudszus, M. Foerster, C. Kroegel, I. Wolf and G. Jahreis, Cis-9, Trans-11-CLA exerts anti-inflammatory effects in human bronchial epithelial cells and eosinophils: 
Comparison to Trans-10,Cis-12-CLA and to linoleic acid, Biochim. Biophys. Acta, 2005, 1737, 111-118.

7 M. Rahman, A. Bhattacharya, J. Banu and G. Fernandes, Conjugated linoleic acid protects against age-associated bone loss in C57BL/6 female mice, J. Nutr. Biochem., 2007, 18, 467-474.

8 A. Fontana, B. Spolaore and P. Polverino de Laureto, The biological activities of protein/oleic acid complexes reside in the fatty acid, Biochim. Biophys. Acta, 2013, 1834, 11251143.

9 Z. M. Gao, L. P. Zhu, X. Q. Yang, X. T. He, J. M. Wang, J. Guo, J. R. Qi, L. J. Wang and S. W. Yin, Soy lipophilic protein nanoparticles as a novel delivery vehicle for conjugated linoleic acid, Food Funct., 2014, 5, 1286-1293.

10 C. Fernandez-Avila, E. Arranz, A. Guri, A. J. Trujillo and M. Corredig, Vegetable protein isolate-stabilized emulsions for enhanced delivery of conjugated linoleic acid in Caco-2 cells, Food Hydrocolloids, 2016, 55, 144-154.

11 K. Kishita, K. Ibaraki, S. Itakura, Y. Yamasaki, N. Nishikata, K. Yamamoto, M. Shimizu, K. Nishiyama and M. Yamasaki, Preparation of Conjugated Linoleic Acid Microemulsions and their Biodistribution, J. Oleo Sci., 2016, 65(11), 949-954.

12 B. Rasti, A. Erfanian and J. Selamat, Nanoliposomal encapsulated omega- 3 fatty acids and their applications in food, Food Chem., 2017, 230, 690-696.

13 L. Salcedo-Sandoval, S. Cofrades, C. Ruiz-Capillas, A. D. Matalanis, D. J. McClements, E. A. Decker and F. Jiménez-Colmenero, Oxidative stability of n-3 fatty acids encapsulated in filled hydrogel particles and of pork meat systems containing them, Food Chem., 2015, 184, 207-213.

14 M. Semenova, Advances in molecular design of biopolymer-based delivery micro/nanovehicles for essential fatty acids, Food Hydrocolloids, 2017, 68, 114-121.

15 A. M. M. Costa, J. C. Nunes, B. N. B. Lima, C. Pedrosa, V. Calado, A. G. Torres and A. P. Pierucci, Effective stabilization of CLA by microencapsulation in pea protein, Food Chem., 2015, 168, 157-166.

16 H. R. Jiang and N. Liu, Self-assembled $\beta$-lactoglobulin-conjugated linoleic acid complex for colon cancer-targeted substance, J. Dairy Sci., 2010, 93(9), 3931-3939.

17 F. F. Visentini, O. E. Sponton, A. A. Perez and L. G. Santiago, Formation and colloidal stability of ovalbumin-retinol nanocomplexes, Food Hydrocolloids, 2017, 67, 130-138.

18 O. E. Sponton, A. A. Perez and L. G. Santiago, Protein-polysaccharide associative phase separation applied to obtain a linoleic acid dried ingredient, Food Hydrocolloids, 2017, 71, 158-167.

19 A. S. Pierre, M. Minville-Walz, C. Fèvre, A. Hichami, J. Gresti, L. Pichon, S. Bellenger, J. Bellenger, F. Ghiringhelli, M. Narce and M. Rialland, Trans-10, cis-12 conjugated linoleic acid induced cell death in human colon cancer cells through reactive oxygen species-mediated ER stress, Biochim. Biophys. Acta, 2013, 1831, 759-768.
20 O. E. Sponton, A. A. Perez, C. R. Carrara and L. G. Santiago, Linoleic acid binding properties of ovalbumin nanoparticles, Colloids Surf., B, 2015, 128, 219-226.

21 O. E. Sponton, A. A. Perez, C. R. Carrara and L. G. Santiago, Complexes between linoleic acid and ovalbumin nanoparticles: stoichiometric, kinetic and thermodynamic aspects, Food Chem., 2016, 211, 819-826.

22 M. Minekus, M. Alminger, P. Alvito, S. Ballance, T. Bohn, C. Bourlieu, F. Carriére, R. Boutrou, M. Corredig, D. Dupont, C. Dufour, L. Egger, M. Golding, S. Karakaya, B. Kirkhus, S. Le Feunteun, U. Lesmes, A. Macierzanka, A. Mackie, S. Marze, D. J. McClements, O. Menard, I. Recio, C. N. Santos, R. P. Singh, G. E. Vegarud, M. S. J. Wickham, W. Weitschies and A. Brodkorb, A standardised static in vitro digestion method suitable for food - an international consensus, Food Funct., 2014, 5(6), 1113-1124.

23 O. E. Sponton, A. A. Perez, I. V. Ramel and L. G. Santiago, Protein nanovehicles produced from egg white. Part 1: Effect of $\mathrm{pH}$ and heat treatment time on particle size and binding capacity, Food Hydrocolloids, 2017, 73, 67-73.

24 J. Schindelin, I. Arganda-Carreras, E. Frise, V. Kaynig, M. Longair, T. Pietzsch, S. Preibisch, C. Rueden, S. Saalfeld, B. Schmid, J. Y. Tinevez, D. J. White, V. Hartenstein, K. Eliceiri, P. Tomancak and A. Cardona, Fiji: an open-source platform for biological-image analysis, Nat. Methods, 2012, 9(7), 676-682.

25 K. Pan, H. Chen, P. M. Davidson and Q. Zhong, Thymol Nanoencapsulated by Sodium Caseinate: Physical and Antilisterial Properties, J. Agric. Food Chem., 2014, 62, 1649-1657.

26 Z. Li, T. Gu, B. Kelder and J. J. Kopchick, Analysis of fatty acids in mouse cells using reversed-phase high-performance liquid chromatography, Chromatographia, 2001, 54(7/ 8), 463-467.

27 E. Murru, E. Angioni, G. Carta, M. P. Melis, S. Spada and S. Banni, in Advances in Conjugated Linoleic Acid Research, Volumne 2, ed. J. L. Sebedio, W. W. Christie and R. O. Adlof, AOCS Press, Champaign (IL), 2003, vol. 7, pp. 94-100.

28 E. Angioni, G. Lercker, N. G. Frega, G. Carta, M. P. Melis, E. Murru, S. Spada and S. Banni, UV spectral properties of lipids as a tool for their identification, Eur. J. Lipid Sci. Technol., 2002, 104, 59-64.

29 M. L. Anson and A. E. Mirsky, The estimation of pepsin with haemoglobin, J. Gen. Physiol., 1932, 16(1), 59-63.

30 M. L. Anson, The estimation of pepsin, trypsin, papain, and cathepsin with haemoglobin, J. Gen. Physiol., 1938, 22(1), 79-89.

31 B. C. W. Hummel, A modified spectrophotometric determination of chymotrypsin, trypsin, and thrombin, Can. J. Biochem. Physiol., 1959, 37(12), 1393-1399.

32 G. Koutina, C. A. Ray, R. Lametsch and R. Ipsen, The effect of protein-to-alginate ratio on in vitro gastric digestion of nanoparticulated whey protein, Int. Dairy J., 2018, 77, 10-18.

33 S. Mun, J. Kim, D. J. McClements, Y. R. Kim and Y. Choi, Fluorescence imaging of spatial location of lipids and pro- 
teins during digestion of protein-stabilized oil-in-water emulsions: A simulated gastrointestinal tract study, Food Chem., 2017, 219, 297-303.

34 O. E. Sponton, A. A. Perez, C. R. Carrara and L. G. Santiago, Impact of environment conditions on physicochemical characteristics of ovalbumin heat-induced nanoparticles and on their ability to bind PUFAs, Food Hydrocolloids, 2015, 48, 165-173.

35 M. Weijers, P. A. Barneveld, M. A. Cohen Stuart and R. W. Visschers, Heat-induced denaturation and aggregation of ovalbumin at neutral $\mathrm{pH}$ described by irreversible first-order kinetics, Protein Sci., 2003, 12, 2693-2703.

36 T. Croguennec, A. Renault, S. Beaufils, J. Dubois and S. Pezennec, Interfacial properties of heat-treated ovalbumin, J. Colloid Interface Sci., 2007, 31, 627-636.

37 N. Matsudomi, H. Takahashi and T. Miyata, Some structural properties of ovalbumin heated at $80{ }^{\circ} \mathrm{C}$ in the dry state, Food Res. Int., 2001, 34(2-3), 229-235.

38 I. J. Joye, G. Davidov-Pardo and D. J. McClements, Nanotechnology for increased micronutrient bioavailability, Trends Food Sci. Technol., 2014, 40(2), 168-182.

39 H. Singh, A. Ye and M. J. Ferrua, Aspects of food structures in the digestive tract, Curr. Opin. Food Sci., 2015, 3, 85-93.

40 I. A. Chen and J. W. Szostak, A kinetic study of the growth of fatty acid vesicles, Biophys. J., 2004, 87, 988-998.

41 P. Walde, R. Wick, M. Fresta, A. Mangone and P. L. Luisi, Autopoietic Self-Reproduction of Fatty Acid Vesicles, J. Am. Chem. Soc., 1994, 26(116), 11649-11654.

42 D. J. McClements and Y. Li, Structured emulsion-based delivery systems: controlling the digestion and release of lipophilic food components, Adv. Colloid Interface Sci., 2010, 159, 213-228.

43 D. Kang, S. R. Ryu, Y. Park, B. Czarnik-Matusewicz and Y. M. Jung, pH-induced structural changes of ovalbumin studied by 2D correlation IR spectroscopy, J. Mol. Struct., 2014, 1069, 299-304.

44 Malvern Instruments Limited, Zeta potential - An introduction in 30 minutes, 2019, https:/www.malvernpanalytical.com/en/learn/knowledge-center/technical-notes/ TN101104ZetaPotentialIntroduction.
$45 \mathrm{H}$. B. Bull and H. Neurath, The denaturation and hydration of proteins: II. surface denaturation of egg, J. Biol. Chem., 1937, 118, 163-175.

46 M. Halwer, Disulfide Cross-links in Denatured Ovalbumin, J. Am. Chem. Soc., 1954, 76(1), 183-186.

47 E. T. Reese and F. M. Robbins, Denaturation of $\beta$-Lactoglobulin by shaking and its subsequent renaturation, J. Colloid Interface Sci., 1981, 83(2), 393-400.

48 S. M. Loveday, X. L. Wang, M. A. Rao, S.-G. Anema, L. Creamer and H. Singh, Tuning the properties of $\beta$-lactoglobulin nanofibrils with $\mathrm{pH}, \mathrm{NaCl}$ and $\mathrm{CaCl} 2$, Int. Dairy J., 2010, 20, 571-579.

49 S. M. Loveday, J. Su, M. A. Rao, S. G. Anema and H. Singh, Effect of Calcium on the Morphology and Functionality of Whey Protein Nanofibrils, Biomacromolecules, 2011, 12, 3780-3788.

50 J. N. Wei, X. A. Zeng, T. Tang, Z. Jiang and Y. Y. Liu, Unfolding and nanotube formation of ovalbumin induced by pulsed electric field, Innovative Food Sci. Emerging Technol., 2018, 45, 249-254.

51 C. J. Cheng, M. Ferruzzi and O. G. Jones, Fate of luteincontaining zein nanoparticles following simulated gastric and intestinal digestion, Food Hydrocolloids, 2019, 87, 229236.

52 G. Martos, P. Contreras, E. Molina and R. Lopez-Fandiño, Egg White Ovalbumin Digestion Mimicking Physiological Conditions, J. Agric. Food Chem., 2010, 58, 5640-5648.

53 K. Nyemb, C. Guérin-Dubiard, D. Dupont, J. Jardin, S. M. Rutherfurd and F. Nau, The extent of ovalbumin in vitro digestion and the nature of generated peptides are modulated by the morphology of protein aggregates, Food Chem., 2014, 157, 429-438.

54 T. Del Castillo-Santaella, J. Maldonado-Valderrama, J. A. Molina-Bolivar and F. Galisteo-Gonzalez, Effect of cross-linker glutaraldehyde on gastric digestion of emulsified albumin, Colloids Surf., B, 2016, 145, 899-905.

55 F. P. Chen, B. S. Li and C. H. Tang, Nanocomplexation between Curcumin and Soy Protein Isolate: Influence on Curcumin Stability/Bioaccessibility and in Vitro Protein Digestibility, J. Agric. Food Chem., 2015, 63, 3559-3569. 